\title{
Study of Excessive Bureaucracy in Construction Projects - Causes of Low Level of Competition and Lengthy Tendering Process: A Case Study of Afghanistan
}

\author{
Sebghatullah Karimi, Zabihullah Zhakfar, Mohammad Ismail Sarwary
}

\begin{abstract}
Excessive bureaucracy has been one of the most challenging issue for infrastructure sector in many countries. Countries are different in terms of their institutional settings, organizational cultures and political balance, and therefore, Afghanistan infrastructure/construction sector is no exception. This phenomenon has negatively impacted the delivery of infrastructure projects and hindering the country to reach its strategic economic goals. There are national projects that have been delayed for several years and the average tendering duration, based on existing researches, is almost 3 times more than the normal practices. This research is aimed to identify major causes of excessive bureaucracy in infrastructure sector that influence the level of competition and tendering duration, and provide technical recommendations for improvements. To do so, 17 factors causing low level of competition and lengthy tendering process have been identified through literature review and interviews. The factors are categorized under two groups; causes of; 1) low level of competition and, 2) lengthy tendering process. A questionnaire was developed and distributed to 80 construction firms. As a result, a response rate of $40 \%$ was achieved. Relative importance index (RII) is used to analyze the survey result. The research findings indicate that the top 5 factors causing excessive bureaucracy in delivering infrastructure/construction projects in Afghanistan and causing low level of competition and lengthy tendering process are: 1) Using traditional methods of procurement instead of electronic system, 2) Lack of accountability by procuring entities, 3) Delay in payments to companies, 4) Slow decision - making by procuring entities and 5) Corruption during the project lifecycle (inception to completion). The outcome of this research will help the government to take necessary actions for eliminating unnecessary steps in the procurement of public infrastructure projects and ultimately improve project delivery. In addition, the research findings will help the construction companies to be fully aware of bureaucracy
\end{abstract}

Revised Manuscript Received on September 15, 2020.

* Correspondence Author

Sebghatullah Karimi*, Department of civil and industrial engineering, Construction faculty, Kabul Polytechnic University, Kabul, Afghanistan. email: s.karimi@kpu.edu.af

Zabihullah Zhakfar, CoST - the Construction Sector Transparency Initiative, Ministry of Economy, Kabul, Afghanistan. email: z.zhakfar2015@gmail.com

Mohammad Ismail Sarwary, Department of civil and industrial engineering, Construction faculty, Kabul Polytechnic University, Kabul, Afghanistan.email: Ym_ismail@kpu.edu.af

(C) The Authors. Published by Blue Eyes Intelligence Engineering and Sciences Publication (BEIESP). This is an open access article under the CC BY-NC-ND license (http://creativecommons.org/licenses/by-nc-nd/4.0/) risks in the procurement process and develop necessary risk mitigation plan for the successful completion of construction projects.

Keyword: Causes of bureaucracy, Infrastructure projects, Level of competition, Lengthy tendering process

\section{INTRODUCTION}

In growth and pave the way to reach their Sustainable Development Goals (SDGs). From transport systems to power-generation facilities and water and sanitation networks, it provides the services that enable society to function and economies to thrive. The critical role of infrastructure can be seen in all three aspects of sustainable development; the economy, the environment and the society [1]. As indicated in Afghanistan's National Infrastructure Plan [2], future economic performance and social development of Afghanistan depends on access to affordable and sustainable energy, irrigation infrastructure, sustainable roads, and technological knowhow and competent institutions. To achieve this economic goal, huge amount of money has been provided and spent for the development of infrastructure through Afghanistan government, international community and donors. According to a report published by CoST: The Infrastructure Transparency Initiative-Afghanistan (CoST-A) $2^{\text {nd }}$ Assurance Report [3], between 2004 and 2018 around 33 billion USD was spent through the national development budget for the rehabilitation and reconstruction of Afghanistan. In addition, the international community invested tremendously on reconstruction of Afghanistan. Reports by the Special Inspector General for Afghanistan Reconstruction [4] shows that since 2002, only the government of USA has contributed $\$ 133$ billion for the reconstruction of Afghanistan. The government priority is to build and improve infrastructure projects in order to achieve its strategic economic development goals. The completion and launch of several large-scale infrastructure projects (such as Salma Dam, Turkmenistan - Afghanistan - Pakistan - India gas pipeline (TAPI), Lapis Lazuli Corridor (Lajaward corridor), the Central Asia - South Asia Power (CASA 1000) project, the Turkmenistan - Uzbekistan - Tajikistan - Afghanistan Pakistan (TUTAP) 500 KV transmission line project, Hairatan Railway,

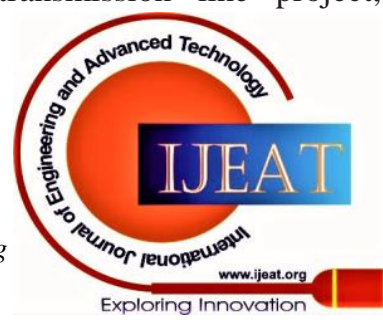




\section{Study of Excessive Bureaucracy in Construction Projects - Causes of Low Level of Competition and Lengthy Tendering Process: A Case Study of Afghanistan}

National ring road, provincial and rural roads and highways, etc.) are examples of infrastructure development in the country which has not only positively affected people's life, but also improved regional connectivity.

Despite all the substantial progress, a number of constrains and challenges still exist in delivering of infrastructure projects. Excessive bureaucracy in public procurement is one those challenges that severely and adversely affected the effectiveness of delivering infrastructure projects in Afghanistan. For instance, the tendering process for Cheghcharan - Gardandewal national highway and Khan Aabad Dam II have taken almost three years and two and half years respectively $[\mathbf{3}, \mathbf{p . 1 6}]$. While according to the international good practices the tendering process should not be exceeded 4 months.

The main reason behind this significant delay is believed to be the existing bureaucratic process in procuring entities and government agencies. In addition, the existing bureaucracy in procurement of infrastructure projects has led to disinclination of construction firm in bidding participation, and therefore, the level of competition, specially, for mega infrastructure projects have been dropped significantly. There are projects that have been announced for several times and only one or two construction firms show interest to participate in bidding process [3, p.18].

There are little studies on bureaucracy, specifically on infrastructure projects, and the subject has been rarely discussed by researchers inside and outside of Afghanistan, therefore, this research is aimed to address this knowledge gap through studying the influence of existing bureaucracy on level of competition and tendering duration of infrastructure projects with a focus to Afghanistan context. To do so, causes of low level of competition and lengthy tendering process will be identified through literature review and interview with pertinent stakeholders. The paper will also provide necessary recommendations to the government for fundamental reforms in the procurement system. In addition, the research findings will help the construction companies to be aware of bureaucracy risks in the procurement process and develop necessary risk mitigation plans for the successful completion of infrastructure/ construction projects.

\section{LETRATURE REVIEW}

The term bureaucrat, bureaucratic, and bureaucracy are clearly invective and nobody calls himself a bureaucrat or his own methods of management bureaucratic [5]. These words are always applied with an opprobrious connotation.

Historically, Max Weber defined the term bureaucracy. He described it as technically superior to all other forms of organization and hence necessary to large, complex enterprises. The word "bureaucracy" stems from the word "bureau", used from the early 18th century in Western Europe to refer to an office or a workplace, where officials worked [6]. Bureaucracy is the administrative structure and set of regulations in place to control (rationalize, render effective and professionalize) activities, usually in large organizations and government. It promotes efficiency and enable the environment for operation [7]. However, they always imply a disparaging criticism of persons, institutions or procedures,

and therefore, nobody doubt that bureaucracy is thoroughly bad and that it should not exist in a perfect world [5].

Bureaucracy has been one of the most challenging issue in many countries. Delays and inefficiency of public agencies feed into the feelings of dissatisfaction common to many citizens in a wide range of countries differing in terms of their institutional settings, organizational cultures and political balance [8]. Bureaucracy has been blamed for many of the failures of public intervention, and those who complain about its inadequacy range from Nobel Prize winning scientists to D-Day2 veterans, as well as entrepreneurs and families, taxpayers and recipients of welfare subsidies [8]. This phenomenon has adversely impacted on public service delivery and the activity of entrepreneurs. A close insight on the impact of bureaucracy on public service delivery in Palestine has found bureaucratic procedures as a challenge in the government institution which scored the effectiveness of service delivery as $70.90 \%$ and recommend that Palestinian Government should reconsider the series of procedures for service delivery operations to become more easily and less complicate [9].

According to Tamrakar [10], scarcity of information and problematic guidelines with hierarchical authorities could be further obstacles to citizens/ customers in dealing with government services. This creates the frustration, dissatisfaction among citizens toward government. Francu [11] identified bureaucracy as an obstacle for young entrepreneurs on the development of businesses domains in Romania. Complications created by the bureaucracy made difficult the attracting of new investors and development of new business opportunities. The author summarizes that bureaucratic phenomenon in public institutions has been affected business environment and entrepreneurs in Romania in different ways. Other researches demonstrate that how excessive government requirements for starting a business can dramatically slow down the entry of new enterprises [12].

Infrastructure sector is another area which is negatively affected by bureaucracy. According to Decarlos et al [12], about 15 percent of world GDP spent every year on public procurement, and therefore, reducing inefficiencies in public procurement might yield significant costs saving and better public services. Based on a research by John et al [13] in Nigeria, rigid bureaucracy in the procurement process of design and build (D\&B) type of contract is one of the most important factors delays construction projects. Olusola and Oluwaseyi [14] also identified bureaucracy as a major risk for contractors when it comes to cash flow and significantly influence the delivery of infrastructure projects. This includes excessive procedures of government approvals, bureaucracy of government as risks related to government policy/agency. This excessive bureaucracy could lead to delays and overruns and reducing the actual work [15]. Different studies identified excessive bureaucracy as the major source of corruption. Archer \& Verster [15] (As cited in Bowen et al 2007) explain the bureaucracy for obtaining official approvals and permits as one of the issues which make construction sector prone to unethical behavior.

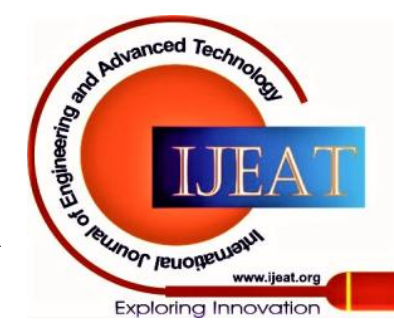


Due to several reasons, public procurement has been alleged as an area of waste and corruption. According to Julius [16], Uganda suffers five types of corruption which are origin from either governance or bureaucratic management system. Corruption in procurement is one of those types which causes financial loss of approximately 15.2 million dollars in Uganda. In a close study on the effects of bureaucracy over business environment in Romania, corruption, lack of transparency, misinformation, time lost and the bureaucratic behavior have been identified as the main adverse effects of bureaucracy in opening business [11]. According to Silaban [17] low capacity of bureaucrats is one of obstacles in process of bureaucratic reforms in Indonesia.

In Afghanistan, generally, there is not enough evidence explaining bureaucracy and its impact on multi-dimensions, especially in infrastructure/ construction sector. However, the challenges which has been created due to bureaucratic performance of state agencies, particularly procuring entities, has been discussed in a few academic research papers. A study on significant factors caused delay in construction projects in Afghanistan states that excessive bureaucracy in project owner operation and bureaucracy in payment process in the government agencies are identified as common causes of delay in construction sector [18]. Furthermore, CoST Afghanistan researches $[3, \mathbf{p . 1 7}, 46]$ on infrastructure projects indicates that bureaucracy in Afghanistan state agencies is one of the reasons behind long tendering process of infrastructure projects. The report concluded that the lengthy tendering process leads to disinclination of construction firms to participate in bidding process, and therefore, it's hard for the government to obtain value for many in public projects.

\section{RESEARCH DESIGN AND METHODOLOGY}

The research is commenced with in-depth review of literature to provide a comprehensive understanding of bureaucracy in procurement of infrastructure projects and also to be used as the underlying foundation for the design of this research and its research instrument. The nature of Afghanistan's bureaucracy and economic environments, which are influencing the procurement of infrastructure projects, are investigated. Case studies on bureaucracy in Uganda, Romania and Indonesia, and other countries have been used to find the closest precedents from which lessons can effectively be learned. To finalize and confirm the influence of current bureaucracy on level of competition and procurement of infrastructure projects, 7 limited interviews were managed to have their views on the root causes of bureaucracy during procurement of projects. Interviewees include construction mangers, procurement mangers and project designers. Based on the result of the interviews, some new items were added to the list, merged with each other, split into more items, changed, modified, or omitted. This vast literature review, case studies and interviews with related stakeholders provide the information and foundation for identifying the key factors causing excessive bureaucracy in procurement of infrastructure projects. The results were then used to develop the main research instrument, a questionnaire survey. The questionnaire was aimed at the top construction companies involved in the construction industry. Participants were carefully selected based on their reputation, experience and expertise in the areas pertaining to infrastructure development.

The final version of questionnaire produced including three sections. Section one includes the demography of the respondents and organizations in order to map out their experience, position and types of projects. Section two includes factors that causes bureaucracy and influence the level of competition and tendering process. The last section focused on collecting respondents' perceptions, views and opinions for improving the procurement of infrastructure projects through reforming in existing bureaucracy. List of factors causing bureaucracy in infrastructure sector is indicated in Table-1. The factors are further categorized into two groups; 1) Level of competition and 2) Tendering process related causes.

\section{Table- 1: Factors Causing Excessive Bureaucracy in Infrastructure Sector}

\begin{tabular}{|c|c|c|}
\hline No & \multicolumn{2}{|c|}{$\begin{array}{l}\text { Factors Causing Excessive Bureaucracy in Infrastructure } \\
\text { Sector }\end{array}$} \\
\hline 1 & \multirow{11}{*}{ 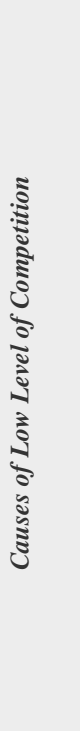 } & Slow decision-making by procuring entities \\
\hline 2 & & Complicated procurement process \\
\hline 3 & & Lack of trust to procurement processes \\
\hline 4 & & Lack of accountability in procuring entities \\
\hline 5 & & $\begin{array}{l}\text { Lack of companies awareness of the bidding } \\
\text { announcement }\end{array}$ \\
\hline 6 & & $\begin{array}{l}\text { Lack of market capacity assessment while preparing } \\
\text { contract condition }\end{array}$ \\
\hline 7 & & Inflexibility in bidding evaluation criteria \\
\hline 8 & & Delay in payments to construction companies \\
\hline 9 & & $\begin{array}{l}\text { Non- sharing of procurement plan with construction } \\
\text { companies in advance }\end{array}$ \\
\hline 10 & & $\begin{array}{l}\text { Lack of reasonable and fair allocation of risks in } \\
\text { public contracts }\end{array}$ \\
\hline 11 & & Lack of eligible bidders in the market \\
\hline 12 & \multirow{6}{*}{ 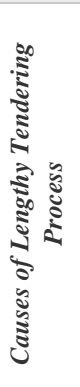 } & $\begin{array}{l}\text { Using traditional procurement method instead of } \\
\text { electronic system }\end{array}$ \\
\hline 13 & & Low capacity of procuring entities \\
\hline 14 & & Inadequate coordination between stakeholders \\
\hline 15 & & Corruption \\
\hline 16 & & Submitting incomplete documents by bidders \\
\hline 17 & & Complex procurement process \\
\hline
\end{tabular}

\section{DATA ANALYSIS}

The Relative Important Index has been used to analyze the data and rank the respondent perceptions. According to Long, Lee \& Lee [19] to rank different factors from various groups of causes the Relative Importance Index is an appropriate index for achieving this aim.
Blue Eyes Intelligence Engineering and Sciences Publication (C) Copyright: All rights reserved.

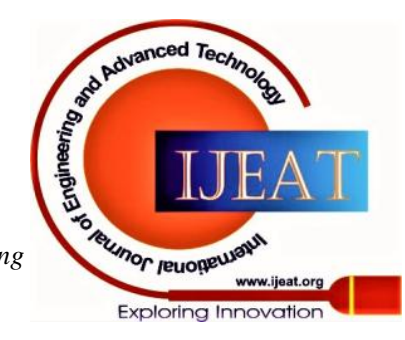




\section{Study of Excessive Bureaucracy in Construction Projects - Causes of Low Level of Competition and Lengthy Tendering Process: A Case Study of Afghanistan}

It analyses the ratings received through the questionnaires and establishes a mean rating point for each factor [20].

Using the below equation, the RII has been calculated:

$$
R I I=\frac{\sum W}{A \times N}
$$

Where $\mathrm{W}$, represent the Likert 5 - point scale given to each factor by each respondent (1=Very Low Impact, 2=Low Impact, 3=Normal Impact, 4=High Impact and 5=Very High Impact). A is the Highest rate ( 5 for this study) and finally $\mathrm{N}$ indicate the total number of samples collected.

\section{RESPONDENT PROFILE}

In the questionnaire survey method, background of the respondents signifies the data reliability [20]. Therefore, in-depth analysis of participants' demographic profile was conducted. Using the Survey Monkey online web domain, a total number of 80 questionnaires were distributed to the private construction firms. Out of 80 distributed questionnaire, 32 were successfully completed, which indicates a response rate of $40 \%$. The questionnaire was available almost for 4 weeks and several follow ups have been achieved by authors to increase participation level.

Fig. 1 indicates respondent's experience in infrastructure sector. As it can be seen, $45.16 \%$ of the respondents have more than 10 years' experience in infrastructure sector. This followed by respondents that have experience of between 5 10 years and 5-2 years which represent a percentage of $19.35 \%$ for each equally. Respondents with less than 2 years' experience represent only $16.15 \%$ of the survey.

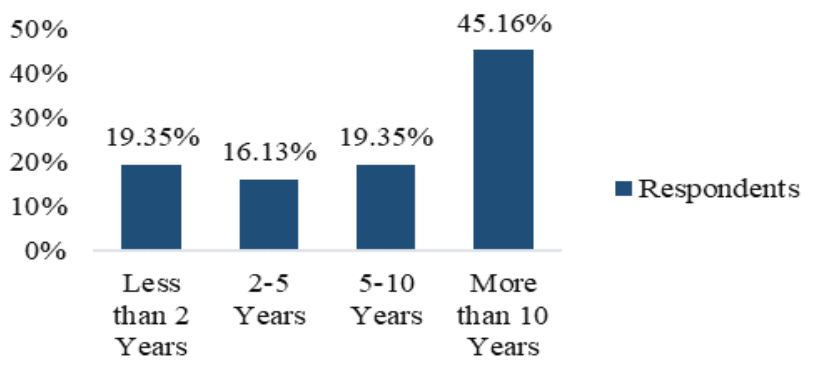

Fig. 1. Respondent Experience

Participants were also asked to score type of project Implemented by them. Diversity in project types support bureaucracy investigation in different projects and state agencies. The analysis of data shows that most of participants were involved in building projects such as School, Hospitals and Houses with a score of $25 \%$. This followed by Roads and public infrastructure such as Bridge, Dam and Canals with a score of $15 \%$ and $14 \%$ respectively. Fig. 2 indicates the types of project implemented by respondents.

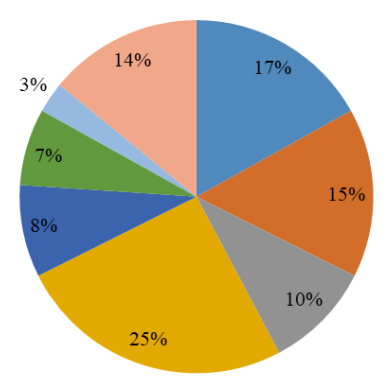

$$
\begin{aligned}
& \text { - Roads } \\
& \text { - Public Infrastructures (Bridge, } \\
& \text { Dam, Canal) } \\
& \text { —Irrigation and Agriculture Canals } \\
& \text {-Buildings (Schools, Hospitals and } \\
& \text { Houses) } \\
& \text { - Water Supply and Canalization } \\
& \text {-Survice (Survey, Design and } \\
& \text { Monitoring) } \\
& \text {-Substations and Transmission } \\
& \text { Lines } \\
& \text { Other }
\end{aligned}
$$

Fig. 2. Types of Projects Implemented by Respondent

\section{DISCUSSION OF FINDINGS}

The aim of this research is to identify significant causes of excessive bureaucracy in infrastructure projects with a focus on level of competition and tendering process. To achieve this aim, significant factors leading to low level of competition and lengthy tendering process of infrastructure projects have been identified through literature review and interview with stakeholders. A total number of 17 factors identified, which is depicted in Table-2. The Relative Important Index has been utilized to analyze and rank the importance of these factors.

The findings of the research show that the top 5 factors causing excessive bureaucracy in infrastructure projects and lead to low level of competition and lengthy tendering process are: 1) Using traditional procurement method, 2) Lack of accountability by procuring entities, 3) Delay in payments to construction companies. 4) Slow decision-making by procuring entities, 5) Corruption.

Paper Work and Utilizing Traditional Methods in procuring entities with an overall relative importance index of 0.863 has ranked the first important factor delaying the tendering process of infrastructure project. Procuring entities still utilize traditional methods (paper work) widely for procurement of infrastructure projects from inception to completion. For instance, in the bidding evaluation process, the project owner (procuring entities) issue an official letter addressing subjected procuring entities to confirm the bidders' similar projects. It takes several months to get the confirmation and plunge ahead the process. In addition, due to the bureaucratic process, bids are not often evaluated within the specific time. According to Afghanistan procurement law and regulation, each bidding process should be evaluated within one month, and could be extended one more month if really needed. However, according to CoST-A 2nd Assurance Report [2, p.17], communication of bidding results between procuring entities, National Procurement Authority (NPA) and National Procurement Commission (NPC) is boreoarctic and time-consuming. Fig. 3 shows the tendering evaluation process. Lack of accountability in procuring entities" with overall Relative Importance Index of 0.825 was the key factor leading to low level of competition. Delay in procurement of infrastructure project results to the disinclination of private firms to participate in the bidding process. According to CoST-A 2nd Assurance Report [2, p.17], the bid guarantee usually issues for a validity period of 3 months, one month extendable, however, due to the lengthy tendering process, it becomes invalid and create new challenges. Invalidation of bid guarantee requires all the bidders to update their bid guarantees. For instance, it took 16 months for the tendering of Weir and Canal Construction of Nahr - e - Shahi, Behsod, Nangarhar Province [2, p.17], whilst during this lengthy process, no one allowed to withdraw its bid guarantee and utilize it in another bidding process.

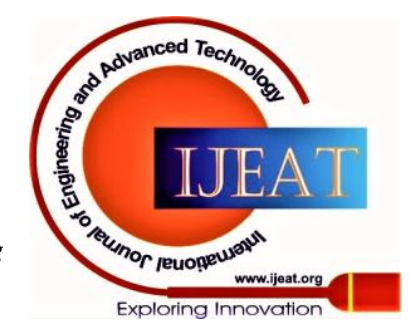


Table- 2: Overall RII and Ranking of Factors Causing Excessive Bureaucracy

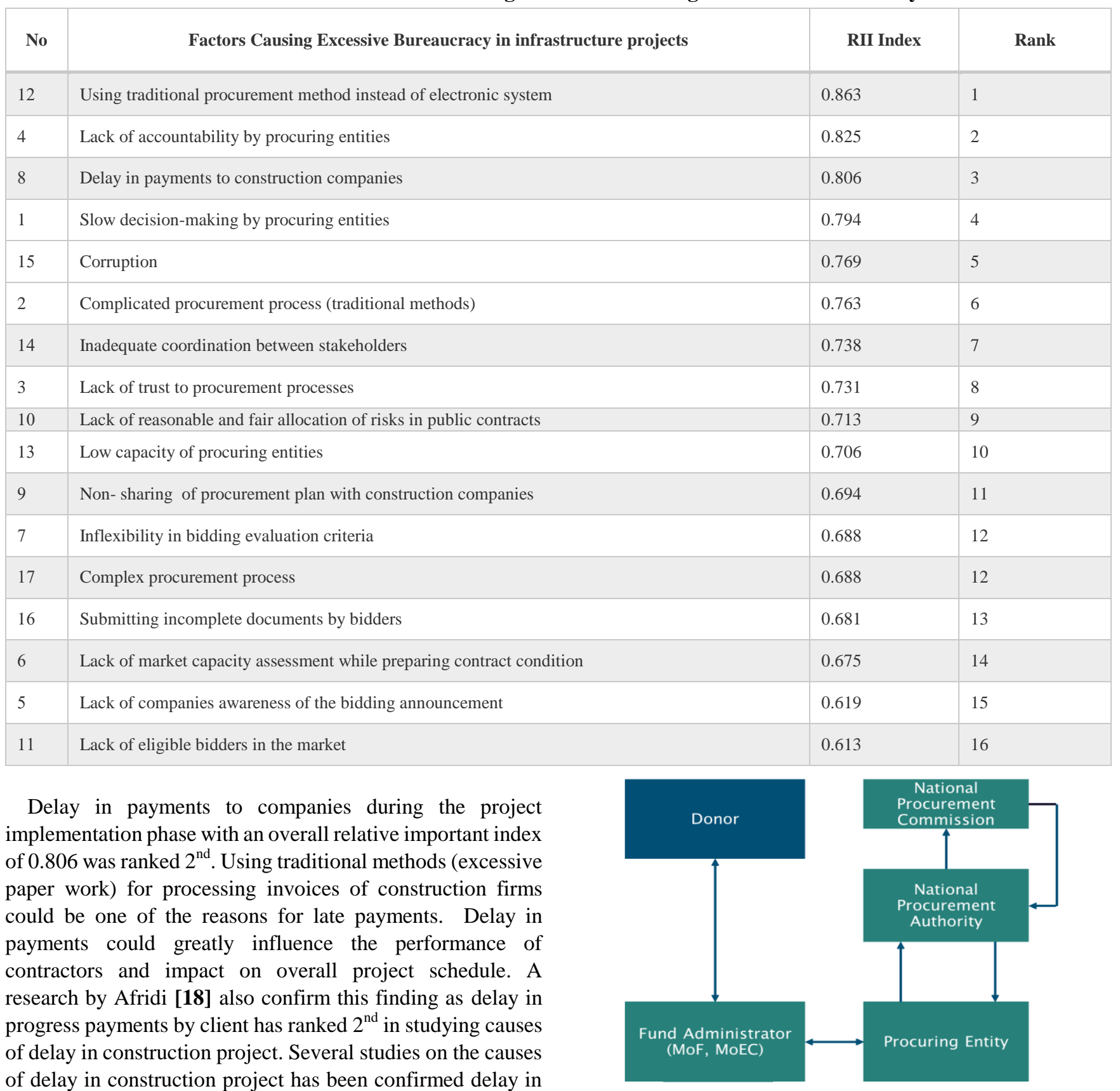
payments to contractors as a key factor for changes in project schedule. Slow decision-making in procuring entities with an overall Relative Importance Index of 0.794 has contributed as the third key factor influencing level of competition. Intervention of several entities in the procurement and contracting process of infrastructure project highly results to slow decision making and create distances between government and construction firms. According to CoST-A $2^{\text {nd }}$ Assurance Report [3, p.17], projects over a certain threshold (more than AFN 100 million) are usually evaluated in two stages.

Fig. 3. Over threshold Project Evaluation Process, adopted from CoST 2nd Assurance Report.

In the first stage, the procuring entity prepare the bid documents, announce the project and evaluate the bids. In the second stage, the bid evaluation report is submitted to the National Procurement Authority (NPA) and subsequently to National Procurement Commission (NPC) for approval (Fig. 3). In this process sometimes donors can get involved which can cause further delays in the tendering process. The organizational bureaucracy of infrastructure procurement is depicted in Fig. 3. Many construction firms argue that large number of projects contracts from one side, and inadequate availability of NPC from another side basically influenced the decision making process for award of infrastructure projects on time.

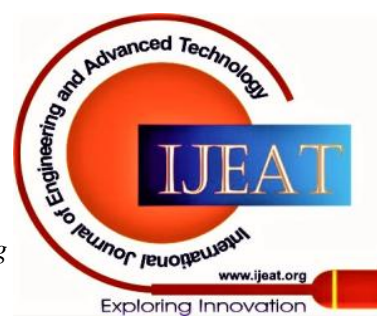




\section{Study of Excessive Bureaucracy in Construction Projects - Causes of Low Level of Competition and Lengthy Tendering Process: A Case Study of Afghanistan}

The complicated hierarchy and inexplicit organizational structure get the contracts to be postponed for several months if not years.

Corruption in procuring entities with an overall Relative Important Index of 0.769 is considered the $4^{\text {th }}$ key factor causing low level of competition. Corruption in public procurement and infrastructure sector is believed as one of the most important challenges in Afghanistan. The World Bank Enterprise Survey on Corruption shows that more than 23 per cent of companies in East Asia, South Asia, the Middle East and North Africa (MENA) region and sub-Saharan Africa have received a bribe request from the public sector [21]. As a concrete base for economic growth development, reducing poverty and delivering better services and goods to the markets, governments spent huge amount of money and private sector make massive investment for developing infrastructure sector, yet corruption is an enormous treat for this funding and investments. According to the Organization for Economic Co-operation and Development [22], government procurement characterizes $29 \%$ of government expenditure for its members and $13 \%$ of their total GDP. The OECD identifies procurement as the government activity most vulnerable to waste, fraud and corruption. Corruption highly accrues in different sizes and types the procurement of infrastructure projects. Afghanistan is a country with high levels of corruption. Collusion, nepotism, racism and requesting bribe is the most common types of corruption could highly influence the procurement procedures. Most of the contraction firms willingly pay bribe for accelerating their administrative work, particularly during processing of payments by procuring entities.

\section{GROUP RANKING OF CUAUSES OF BUREAUCRACY}

The causes of bureaucracy in infrastructure projects were also ranked under each sources (group) of causes. As shown in Table-3, there are 11 factors identified under "level of competition" group. "Lack of accountability in procuring entities" with an overall RII $=0.828$ identified as the most important factor causing bureaucracy and influence the level of competition. This is followed by "Complicated procurement process (traditional methods) with an overall RII $=0.806$. The Afghanistan infrastructure portfolio is characterized numerous projects facing significant delays and poor performance. Procurement/Contracting delays has been reported one of the main reason for poor performance [2, p.5]. Table 4 presents the causes of lengthy tendering process.

Table- 3: Ranking of Factors Affecting the Level of Competition

\begin{tabular}{|l|l|l|}
\hline $\begin{array}{l}\text { Causes of Low Level of Competition in } \\
\text { Procurement of Infrastructure Projects }\end{array}$ & Index & Rank \\
\hline Slow decision-making by procuring entities & 0.825 & 1 \\
\hline Complicated procurement process & 0.806 & 2 \\
\hline Lack of trust to procurement processes & 0.794 & 3 \\
\hline Lack of accountability in procuring entities & 0.769 & 4 \\
\hline $\begin{array}{l}\text { Lack of companies awareness of the bidding } \\
\text { announcement }\end{array}$ & 0.731 & 5 \\
\hline $\begin{array}{l}\text { Lack of market capacity assessment while preparing } \\
\text { contract condition }\end{array}$ & 0.713 & 6 \\
\hline
\end{tabular}

Retrieval Number: 100.1/ijeat.A17071010120

DOI:10.35940/ijeat.A1707.1010120

Journal Website: www.ijeat.org

\begin{tabular}{|l|l|l|}
\hline Inflexibility in bidding evaluation criteria & 0.694 & 7 \\
\hline $\begin{array}{l}\text { Delay in payments to construction companies } \\
\begin{array}{l}\text { Non- sharing of procurement plan with construction } \\
\text { companies }\end{array}\end{array}$ & 0.688 & 8 \\
\hline $\begin{array}{l}\text { Lack of reasonable and fair allocation of risks in } \\
\text { public contracts }\end{array}$ & 0.619 & 10 \\
\hline \begin{tabular}{l} 
Lack of eligible bidders in the market \\
\hline
\end{tabular} & 0.613 & 11 \\
\hline
\end{tabular}

Findings indicates that there 6 factors contributing to delay in tendering process of infrastructure projects. Paper work and utilizing traditional method of procurement instead of electronic system with an overall $\mathrm{RII}=0.863$ has been given the highest respondent rate and ranked $1^{\text {st }}$. This is followed by "Low capacity of procuring entities" with an index of 0.738 .

Table- 4: Ranking of Major Causes of Lengthy Tendering Process

\begin{tabular}{|l|l|l|}
\hline Causes of Lengthy Tendering Process & Index & Rank \\
\hline $\begin{array}{l}\text { Using traditional procurement method instead of } \\
\text { electronic system }\end{array}$ & 0.863 & 1 \\
\hline Low capacity of procuring entities & 0.738 & 2 \\
\hline Inadequate coordination between stakeholders & 0.738 & 3 \\
\hline Corruption & 0.706 & 4 \\
\hline Submitting incomplete documents by bidders & 0.688 & 5 \\
\hline Complex procurement process & 0.681 & 6 \\
\hline
\end{tabular}

\section{CANCLUSION AND RECOMMENDATIONS}

This research was specifically aimed to study the influence of excessive bureaucracy on level of competition and tendering process of infrastructure projects in the context of Afghanistan. To do so, 17 causes of low level of competition and lengthy tendering process have been identified through literature review and interview with construction companies. The causes of bureaucracy in infrastructure projects were categorized under two groups. 11 causes of low level of competition and 6 causes of lengthy tendering process were identified. The results were then used to develop the main research instrument, a questionnaire survey and distributed to 80 respondents. The respondents were asked to ranked the importance of these factors on level of competition and tendering process. The Relative Important Index has been used to analyze the data. The result of the survey shows that the 5 top factors causing excessive bureaucracy in infrastructure/construction sector and significantly influence the level of competition and tendering duration are: 1) Using traditional methods instead of electronic system, 2) Lack of accountability in procuring entities, 3) Delay in payments to companies, 4) Slow decision - making by procuring entities and 5) Corruption during the project lifecycle (inception to completion). The following recommendations are made for improving level of competition and tendering process and reduce the excessive bureaucracy in infrastructure/construction sector: 
1. To improve the effectiveness and efficiency of public procurement, it would be good if the National Procurement Authority build the technical capacity of procuring entities and promote use of E - Procurement for infrastructure projects. This could potentially reduce the tendering duration and promote construction firms' engagement. Digitalizing administrative procedures and developing standard forms for electronic reporting could widely help for achieving this goal. Furthermore, extending line ministries contract award authority could potentially speed up the decision making process, especially it would be effective when it comes about approval of amendments in contract.

2. To accelerate the payment process to contractors, the procuring entities should seek to establish an integrated mechanism for communication between key stakeholders such as National Procurement Authority, Borrower, Ministry of Finance and Donor. As part of the project planning stage, coordination and communication plan should be developed to identify key stakeholders involved in the project. In the context of Afghanistan, a strong coordination between Contractors, Procuring Entities in different levels; entity level and sector level, National Procurement Authority and Donors is needed to circulate the process on time.

3. Construction firm's engagement in bidding process could be increased if procuring entities reduce rigidity of bid evaluation criterions. Revising bid evaluation criterions in term of annual turnover, similar project and exclusion or reducing of bidding guarantees from the tendering process would potentially be effective for this purpose.

4. Corruption is a negative phenomenon which greatly influence the construction firms' willingness to participate in bidding process. Utilizing e - tendering technology and digitalization of procurement process could potentially reduce the level of corruption and cut off the villains' hands from the processes. Moreover, procuring entities are recommended to undertake concrete steps to fight against corruption and promote the culture of accountability through disclosing infrastructure project data to the public.

\section{REFERENCES}

1. The Economist Intelligence Unit, The Critical Role of Infrastructure for the Sustainable Development Goals, London, UK, 2019. May 01, 2020. [Online]. Available: https://www.unops.org/news-and-stories/publications/the-critical-role -of-infrastructure-for-the-sdgs).।

2. Ministry of Finance, National Infrastructure Plan 2016-21. May 01, 2020. [Online]. Available: http://policymof.gov.af/home/wp-content/uploads/2019/01/Natioal-In frastructure-NPP.pdf

3. CoST - the Infrastructure Transparency Initiative, The Second Assurance Report: Transparency and Accountability in Public Infrastructure Projects, Kabul, Afghanistan, 2019. May 01, 2020. [Online]. Available: www.cost.af

4. Special Inspector General for Afghanistan Reconstruction, Quarterly Report, p.43, SIGAR, Kabul, Afghanistan, 2019. May 01, 2020. Available: https://www.sigar.mil/pdf/quarterlyreports/2019-04-30qr.pdf

5. L. V. MISES, "Introduction," in BUREAUCRACY, USA.: YALE UNIVERSITY PRESS, 1944.

6. M. j. Hashi, The Effect of Bureaucracy on Public Service Delivery in Somalia: Case Study Banadir Region, P.A Dissertation, Dept. of Pub. Adm, MOGADISHU Univ., Somalia, 2015.
7. Prof. P. GRIGORIOU, Bureaucracy: administrative structure and set of regulations in place to control organizational or governmental activities, University of the Aegean.

8. G. Regonini, "Administrative Simplification Between Utopia and Nightmare," in Utopian Discourses Across Cultures: Scenarios in Effective Communication to Citizens and Corporations, M. Bait, M. Brambilla, V. Crestani, Ed., Frankfurt am Main: Peter Lang AG, 2016 , pp. 105-124. [Online]. Accessed May 01, 2020. Available: http://www.jstor.org/stable/j.ctv2t4bv7.10

9. R. Tamrakar, Impact of Citizen Charter in Service Delivery: A Case of District Administration Office, Kathmandu, M.S. Thesis, Dept. of General \& Continuing Edu, North South University, Bangladesh, 2010.

10. S. Z. S. Abdalmenem, The Impact of Bureaucracy on Public Servant's Perspective: Case Study on Land Authority in Gaza, M.S. Thesis, Dept. B. A, Islamic Univ. in Gaza, Gaza, Palestine, 2014.

11. L. G. FRANCU, the effects of bureaucracy over the business environment from Romania, Theoretical and Applied Economics, Volume XXI, No. 2(591), pp. 115-125, 2014.

12. F. Decarolis, L. M. Giuffrida, E. Lossa, V. Mollisi, G. Spagnolo, Bureaucratic Competence and Procurement Outcomes, Aug 13, 2018.

13. I. B. John, O. Oyeyipo, \& O. M. Ajayi, Risk involved in Design and Build Procurement in Nigeria, Proc. of RICS Construction \& Property Conf., Manchester, England, 2011, pp. 957-68.

14. A. Olusola F., \& A. Oluwaseyi A., An Appraisal of Risks Associated with Contractor's Cash Flow and their Impact on Project Delivery in Nigeria, Proc. of RICS Construction \& Property Conf., Manchester, England, 2011, pp. 1601-1611.

15. M. M. Archer, Prof. JJP. Verster, Ethics, Leadership and Education, RICS Construction and Property Conference, Proc. of RICS Construction \& Property Conf., Manchester, England, 2011, pp. 708-714.

16. B. Julius, State, Bureaucracy and Government: Uganda's Opportunities, Challenges and Possible Solutions, Candidate, M.A Democratic Governance and Civil Society, Univ. of Osnabrueck, Germany, 2013.

17. H. Silaban, Bureaucratic Reform in Indonesia: Lesson Learned from Bureaucratic Model in Japan, Int. J. Adv. Res, 5(1), 2096-2105, Hang Lekir I No.8, Senayan, Jakarta 10270, Indonesia, 2016.

18. A. K. Afridi, "Significant factors of Delay in Construction Projects in Afghanistan," M.S. Thesis, Faculty of Economy, Yamaguchi Univ. Yamaguchi, Japan, 2016.

19. L.H. Long, Y.D. Lee \& J. Y. Lee, Delay and Cost Overruns in Vietnam Large Construction Projects: A Comparison with Other Selected Countries. J. of Civil Eng., 12(6), 367-377, 2008.

20. S. Durdyev1, M. Omarov, \& S. Ismail, Causes of delay in residential construction projects in Cambodia, Cogent. Eng., 4: 1291117, 2017.

21. P. McIntyre, Integrity in infrastructure and public procurement: Protecting the public interest, Water Integrity Brief, June 2016.

22. The Organization for Economic Cooperation \& Development, Recommendation of the Council on Public Procurement, Paris, 2015.

\section{AUTHORS PROFILE}

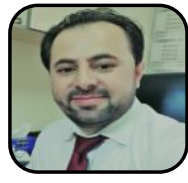

Sebghatullah Karimi holds M.Sc. in Construction Project Management (2012) and B.Sc. in Construction Management (2011) both with Distinction from University of Brighton, United Kingdom, and B.Sc. in Civil Engineering (2006) with distinction from Kabul Polytechnic University (KPU). He is a senior lecturer in KPU and the country manager for CoST: The Construction Sector Transparency Initiative-Afghanistan for the past 12 and 4 years respectively. He has more than 10 years of experience in the construction industry and academia, and has worked for national and international organizations. His research interests cover the construction industry and procurement of construction projects in Afghanistan. Mr. Karimi has presented and published several papers in the national and international journals and conferences in the UK, Australia and Afghanistan, and also published several chapter books, reports and manuals. Mr. Karimi was part of the research team for Scoping Study of CoST Afghanistan which laid the foundation of establishing this initiative and beginning the infrastructure data disclosure culture in the public sector. He also supervised the research team responsible for development of First Assurance Report and led the research for Second Assuean re Revort of CoST Initiative in Afghanistan. 
Study of Excessive Bureaucracy in Construction Projects - Causes of Low Level of Competition and Lengthy Tendering Process: A Case Study of Afghanistan

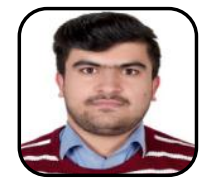

Zabihullah Zhakfar Holds Bachelor degree in Civil Engineering (2018) with distinction from Kabul Polytechnic University (KPU). Mr. Zhakfar also received several trainings and capacity building certificates in Design and Design Review, Energy Efficiency and Thermal Insulation of Buildings from Kabul Polytechnic University and German Society for International Cooperation (GIZ). His research interest is mainly in structural engineering and infrastructure management. He was a member of research team in delivering CoST Afghanistan Second Assurance Report on Transparency and Accountability in Public Infrastructure Projects. Moreover, he has presented an academic article titled "Fibre Reinforced Concrete" in the $16^{\text {th }}$ student academic conference conducting in Kabul Polytechnic University annually. He has been working as a Civil Engineer/Researcher for CoST - The Construction Sector Transparency Initiative since 2019.

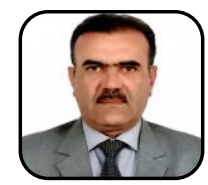

Mohammad Ismail Sarwary holds M.Sc. in Civil Engineering from Kabul Polytechnic University in 1985. He is currently working as Assistants Professor in Kabul Polytechnic University. Mr. Sarwary has over 20 years' experience in academia and construction industry and his research interest covers structural engineering, earthquake engineering and concrete mix design. He has published several papers in national and international journals and attended academic conferences inside and outside of the country. His main publications include "Current practice of earthquake engineering in construction industry in Afghanistan and recommendations", "Assessment of Ductility in Earthquake Resistant Concrete Structures" and "Evaluation of Beams and Columns Behavior in Reinforced Concrete Moment Resistance Frame". Mr. Sarwary is also working as the Head of Civil Engineering Department in Kabul Polytechnic University.

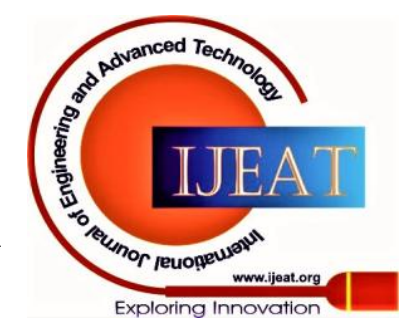

